\title{
Experimental Infection of Swine by Isospora suis Biester 1934 for Species Confirmation
}

\author{
Silvia Maria Oliveira Sayd, Urara Kawazoe ${ }^{+}$
}

\author{
Departamento de Parasitologia, Instituto de Biologia, Unicamp, Caixa Postal 6.109, 13083-970 \\ Campinas, SP, Brasil
}

\begin{abstract}
A survey of Isospora suis performed in 177 faecal samples from 30 swine farms detected thin wall type I. suis oocysts in seven samples. This type of oocyst measuring 23.9 by $20.7 \mathrm{~mm}$ had a retracted thin wall similar to that of the genus Sarcocystis. This type of oocysts, isolated from four different faecal samples, was inoculated in four-five-days-old piglets free of contamination in order to verify the life cycle and pathogenicity of the species. The pigs were kept in individual metal cages and fed with cow milk. Daily faecal collections and examinations were performed until the 21 st day after infection. MacMaster and Sheather's methods were used for oocyst counting and identification. Infected piglets produced yellowish-pasty diarrhoea with slight dehydration. The prepatent and patent periods were respectively from 6 to 9 and 3 to 10 days after infection. Oocyst elimination was interrupted on the 10th and 11 th days after infection with biphasic cycles. Thin and thick wall oocysts were detected in the same faecal samples. Thin walls were not observed in unsporulated oocysts. The observations suggest that this type of oocysts could appear in specific strains which occur in the later stages of their development. These oocysts seem to be responsible for clinical and pathogenic signs of neonatal isosporosis in pigs.
\end{abstract}

Key words: Isospora suis - life cycle - neonatal isosporosis - pathogenicity

Isospora suis has been considered an important enteroparasite of piglets which causes coccidiosis in neonatal swine (Ruzicka \& Andrews 1983). Yellowish-pasty diarrhoea is the most characteristic clinical sign of the disease which is more prevalent in piglets between 5 to 21 days old. It does not respond to any antibiotic treatment (Lindsay 1989) but experiments with an anticoccidial drug toltrazuril have been successfully used experimentally (Mundt 1994) as well as in some swine farms (Kondela et al. 1991, ByeungGie 1995). I. suis oocysts are found in faecal contents of piglets and the diagnosis is based upon their morphology.

A survey of $I$. suis performed in 177 faecal samples from 30 farms (Sayd \& Kawazoe 1996) detected thin wall type oocysts in seven of these samples. This type of oocysts measuring 23.9 by $20.7 \mathrm{~mm}$ had a refracted thin wall similar to that from the genus Sarcocystis (Ruiz \& Frenkel 1976). Biester and Murray (1934) and Vertterling (1965) observed thin wall oocysts in I. suis oocysts but they attributed them to their floatation in Sheather's solution for a long time or osmotic and mechanic

Supported by Capes and FAEP (Unicamp, Brazil). ${ }^{+}$Corresponding author. Fax: +55-19-289.3124. E-mail: urka@correionet.com.br

Received 23 January 1998

Accepted 2 July 1998 pressures of oocysts by the time of faecal examination. Life cycle and oocyst structure of Sarcocystis species were unknown at the time of their articles publication.

In the present study an experimental infection of thin wall type oocysts was performed in piglets for the confirmation of I. suis species characterized by clinical signs, possible small intestine tissue lesions, oocyst structure and life cycle observations.

\section{MATERIALS AND METHODS}

Thin wall oocysts were isolated from four faecal samples collected in swine farms and cultivated according to the method described by Long et al. (1976) with some modifications. Faecal samples were filtered through a metalic sieve of 50 meshes, centrifuged in $800 \mathrm{~g}$ for $5 \mathrm{~min}$ to obtain the pellet and cultivated in $2 \%$ potassium dichromate solution with oxygen aeration at room temperature of about $25^{\circ} \mathrm{C}$ during at least $72 \mathrm{hr}$. This type of oocysts was inoculated in four-five-day-old pigs free of contamination: pig 1 received $6.6 \times 10^{4}$ sporulated oocysts, pig 2 received $10^{3}$ oocysts, and pigs 3 and 4 received $4 \times 10^{4}$ oocysts.

They were kept in individual metal cages and fed with cow milk. Daily observations of pigs for dehydration level, general conditions, faecal consistency and oocyst production were performed until the 21st day after inoculation. MacMaster and Sheather' s methods were used for oocyst identifi- 
cation and counting, respectively. Pigs were killed 21 days after infection for histological observations of their small intestine epithelial cells after fixation in Bouin solution. Tissues were embedded in paraffin wax, cut in transverse sections of about $5 \mathrm{~mm}$ in thickness and stained with haematoxylin and eosin.

\section{RESULTS AND DISCUSSION}

Experimental development of I. suis life cycle in four piglets inoculated with thin wall oocysts revealled semi-pasty to pasty-yellowish diarrhoea from 6 to 14 days after inoculation, progressively, as the main clinical sign. Faecal consistency varied according to the number of oocysts inoculated from normal, semi-pasty, pasty-yellowish and liquid. Pasty faecal consistency was observed in all the piglets although in the pig 2 inoculated with a small number of oocysts the faecal consistency was normal most of the time of infection. In pigs 1 and 4 the faecal consistency was pasty-yellowish from 6 to 14 days after oocyst inoculation but in one day liquid consistency was observed. These results agree with the results described by Lindsay and Blagburn (1994) and also by Blagburn et al. (1991) in experimental infection of miniature swine. Morbidity of $100 \%$ with slight dehydration of infected pigs was observed in the present study but none of them died during the experiment. Histopathological observations of the small intestine 21 days after inoculation showed no alteration of epithelial cells or stages of the parasite, as a consequence of I. suis life cycle development, suggesting a com- plete recovery of infected cells.

The prepatent period of 6 to 9 days and a patent period between 3 to 10 days after inoculation were observed with oocyst production between $10^{4}$ and $9 \times 10^{5}$ per day (Fig. 1). This variation in oocyst production is probably due to the differences on the number of oocysts inoculated in each piglet. The differences in the prepatent and patent periods of $I$. suis were also observed by Robinson et al. (1983), Harleman and Meyer (1984/1985), Souza et al. (1989), Marques (1990).

During the life cycle development of $I$. suis in experimentally infected piglets two peaks of oocyst elimination were observed in pigs 1,2 and 3 with an interruption of oocyst elimination during two or three days between the first and second period of elimination, on the 10th and 11th days after inoculation, showing a biphasic cycle (Fig. 1) which agrees with the Lindsay and Blagburn (1994) observations.

In the present study the daily oocyst counting detected thick wall unsporulated and thin wall sporulated oocysts measuring 23.9 × $20.7 \mathrm{~mm}$ (Fig. 2 ) in the same faecal sample of infected pigs. Thin wall oocysts were not observed in unsporulated ones but only in sporulated ones. These characteristics confirm I. suis species in infected piglets and the oocyst sizes agree with the Biester and Murray (1934) description. They also cited oocysts with the thin wall membrane collapsed around the sporocysts which were attributed to their floatation in Sheather's solution for a long time or due to osmotic and mechanic pressures of oocysts by the

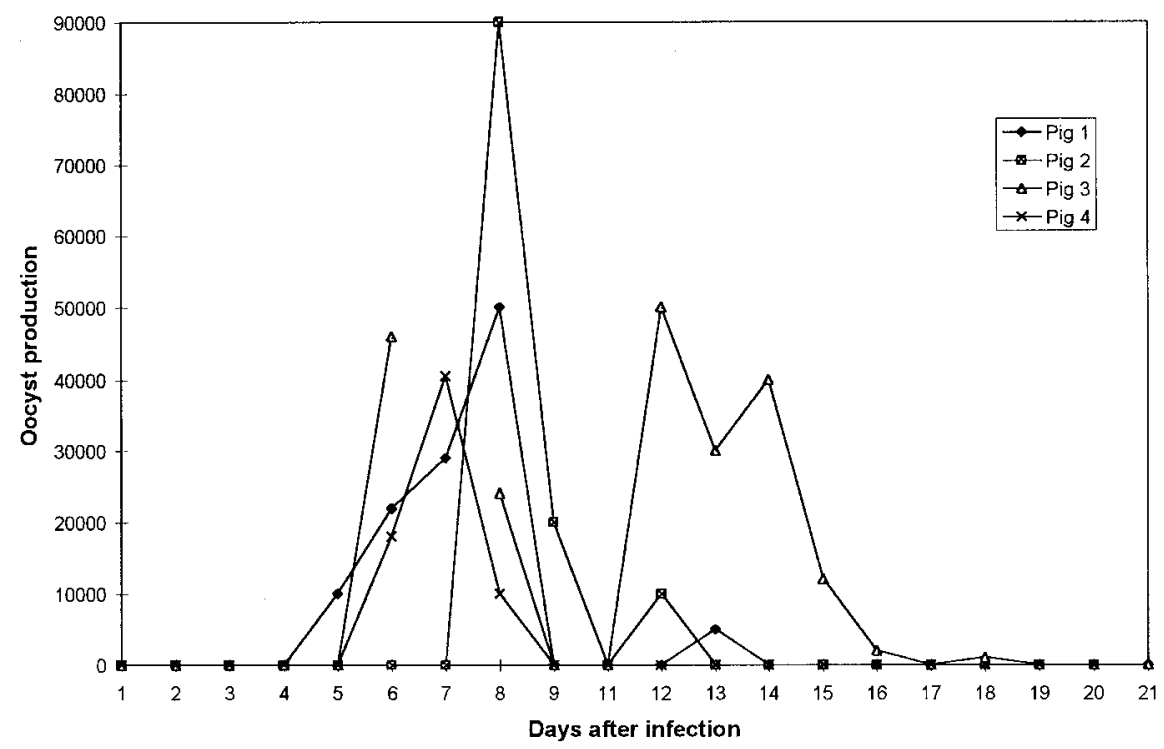

Fig. 1: Isospora suis oocyst production, per day, in four pigs experimentally infected, during the period of 21 days after inoculation. 

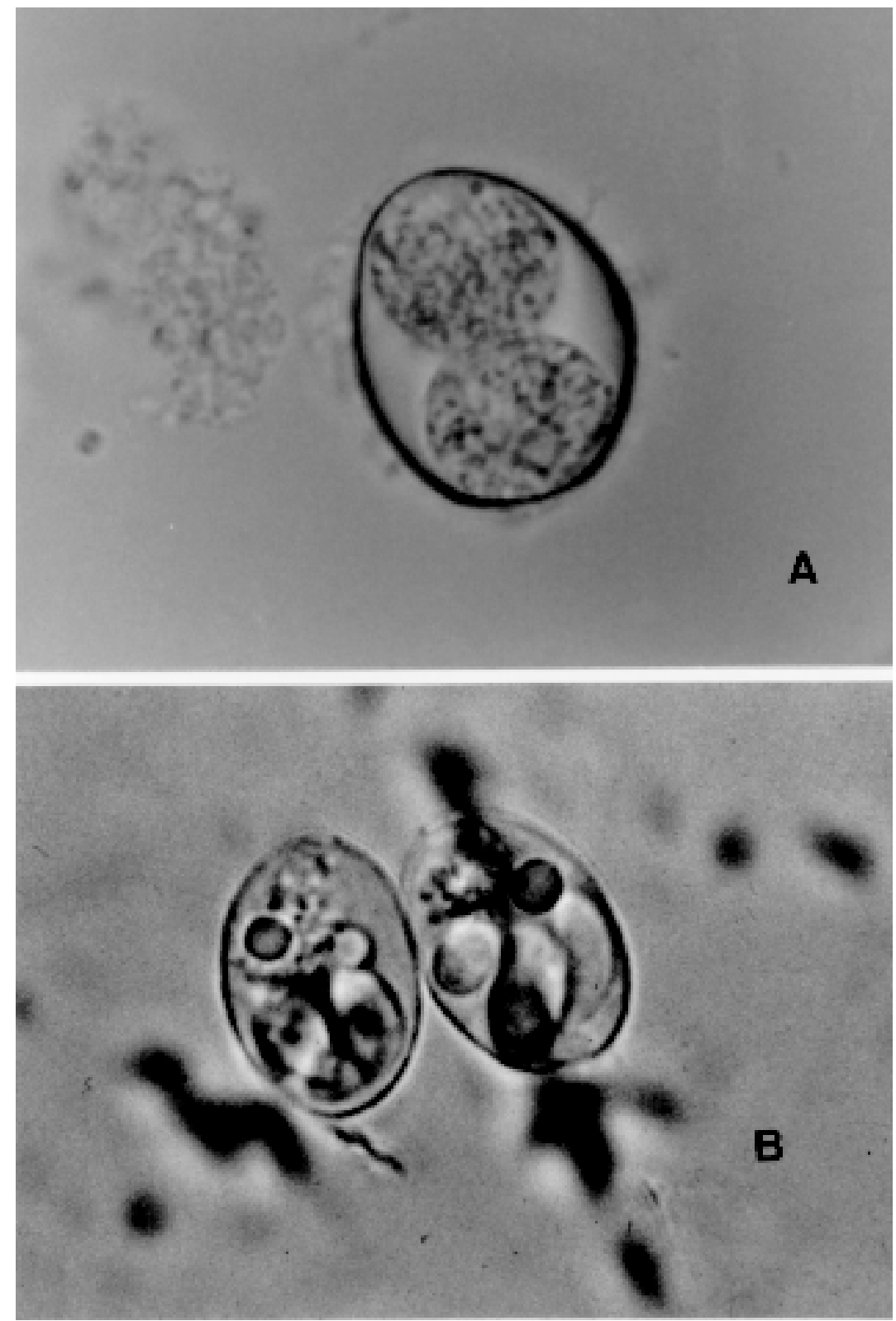

Fig. 2: unsporulated thick wall oocyst (A) and sporulated thin wall oocyst (B) of Isospora suis after experimental inoculation in five-day-old pig $(100 \mathrm{x})$.

time faecal examination was carried out (Biester \& Murray 1934, Vetterling 1965, Lindsay et al. 1980). In the present study, thin wall oocysts were also found in faecal samples submitted to floatation in sucrose or sodium chloride solutions for a short time. This type of oocyst is similar to that of Sarcocystis species although when they pass through the faeces they are already sporulated and usually the sporocysts are already released from the oocyst membrane (Dubey 1976, Ruiz \& Frenkel 1976). However, I. suis oocysts need some time outside the host to become sporulated. Some faecal samples recently collected had oocysts already with two sporoblasts whereas in others a complete rupture of wall membrane with released sporocysts was observed. 
These observations suggest that thin wall type oocysts could appear in specific strains of $I$. suis or could be a characteristic of certain strains which occur in the later stages of their development. These oocysts seem to be responsible for the clinical and pathogenic signs of neonatal isosporosis in pigs.

\section{REFERENCES}

Biester BW, Murray C 1934. Studies in infections enteritis of swine. J Am Vet Med Assoc 85: 207-219.

Blagburn BL, Boosinger TR, Powe TA 1991. Experimental Isospora suis infection in miniature swine. Vet Parasitol 38: 343-347.

ByeungGie K 1995. Efficacy of Baycox (Bay Vi9142) suspension against coccidium Isospora suis in piglets. Kor J Vet Clin Med 12: 129-136 [Ko].

Dubey JP 1976. A review of Sarcocystis of domestic animals and of other coccidia of cats and dogs. JAVMA 169: 1061-1078.

Harleman HJ, Meyer RC 1984/1985. Life cycle of Isospora suis in gnotobiotic and conventionalized piglets. Vet Parasitol 17: 27-39.

Kondela B, Vodstrcilová M, Klimes B, Vladik P, Vítoved J 1991. Use of the coccidiostat toltrazuril (Baycox, Bayer) in coccidiosis in unweaned piglets. Vet Med 36: 657-663 [Cs].

Lindsay DS 1989. Diagnosing and controlling Isospora suis in nursing pigs. Vet Med 84: 443-448.

Lindsay DS, Blagburn BL 1994. Biology of mammalian Isospora. Parasitol Today 10: 214-220.

Lindsay DS, Stuart BP, Wheat BE, Ernst JV 1980. Endogenous development of the swine coccidium, Isos- pora suis Biester 1934. J Parasitol 66: 771-779.

Long PL, Joyner PL, Millard BJ, Norton CC 1976. A guide to laboratory techniques in the study and diagnosis of avian coccidiosis. Fol Vet Lat 6: 201-207.

Marques JL 1990. Aspectos Clínicos, Parasitológicos e Ànatomopatológicos da Isosporose em Leitões Lactentes Inoculados Experimentalmente, Thesis, Escola de Veterinária, Universidade Federal de Minas Gerais, Belo Horizonte, 70 pp.

Mundt HC 1994. Toltrazuril - a coccidial compound against $I$. suis infections in baby pigs, p. 257. Proceedings of the 13th International Pig Veterinary Society Congress, Bangkok, Thailand.

Robinson Y, Morin M, Girard C, Higgins R 1983. Experimental transmission of intestinal coccidiosis to piglets: clinical, parasitological and pathological findings. Can J Comp Med 47: 401-407.

Ruiz A, Frenkel JK 1976. Recognition of cyclic transmission of Sarcocystis muris by cats. J Infec Dis 133: 409-418.

Ruzicka CW, Andrews JJ 1983. Porcine neonatal coccidiosis: a clinical review. Iowa St Vet 45: 90-95.

Sayd SMO, Kawazoe U 1996. Prevalence of porcine neonatal isosporosis in Brazil. Vet Parasitol 67: 169174.

Souza JCA, Marques JL, Lima JD, Sobestiansky J, Nogueira RH 1989. Aspectos clínicos e parasitológicos da isosporose em leitões lactentes inoculados experimentalmente, p. 103. Congresso Brasileiro de Veterinários Especialistas em Suínos. Itapema, Santa Catarina.

Vetterling JM 1965. Coccidia (Protozoa: Eimeriidae) of swine. J Parasitol 51: 897-913. 